\title{
An Improved and Sensitive Method for Vitamin D3 Estimation by RP- HPLC
}

\author{
Subodh Kumar ${ }^{1}$, Diwesh Chawla ${ }^{1}$ and Ashok Kumar Tripathi ${ }^{*}$ \\ ${ }^{1}$ Central Research Laboratory, Multi-disciplinary Research Unit, University College of Medical Sciences, Delhi-110095, India \\ ${ }^{2}$ Biochemistry and Immunology Laboratory, Department of Biochemistry, University College of Medical Sciences, Delhi-110095, India
}

\begin{abstract}
Despite plenty of sunlight, vitamin D deficiency (VDD) in India is an epidemic. 50-90\% populations among all age groups are associated with VDD. Among the common methods (RIA, immunoassay etc.) available for vitamin D estimation, the analytical method like HPLC is considering as a gold standard. In the proposed study, we have developed a RP-HPLC method for the estimation of vitamin D3 with greater precision and accuracy. Separation was achieved on C18 column in isocratic mode using two different mobile phases i.e. acetonitrile: methanol (method I) and methanol: water with $0.1 \%$ formic acid (method II). The column was maintained at $40{ }^{\circ} \mathrm{C}$ and the mobile phase was pumped at flow rate of $0.4 \mathrm{~mL} \mathrm{~min}{ }^{-1}$. The detection of eluent was carried out at $\lambda_{\max } 265 \mathrm{~nm}$. Retention time of vitamin D3 for method I and II was found to be 7.14 and 7.01 minutes, respectively, with $\mathrm{R}^{2}>0.99$. The standard curves were linear over the concentration range of $0.5-5 \mathrm{ng} \mathrm{mL}^{-1}$. The LOD and LOQ values for vitamin $D_{3}$ for method I and II were found to be $1.64,5.02$ and $1.10,3.60 \mathrm{ng} \mathrm{mL}^{-1}$, respectively. The percentage recovery was found to be $69-79 \%$ and $75-87 \%$ for method I and II, respectively. The $\%$ RSD of intra and inter-day precision of method I was found $<2$ and $<7 \%$, whereas, for method II, $<2$ and $<4 \%$ respectively. In conclusion, method II showed greater precision and accuracy and also cost effective, therefore, it can be used for vitamin $\mathrm{D}_{3}$ estimation at laboratory scale.
\end{abstract}

Keywords: Vitamin D; RP-HPLC; Development and validation; DAD

\section{Introduction}

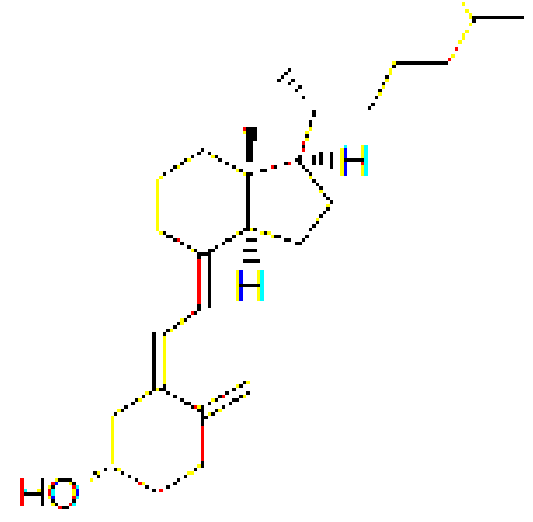

\section{Vitamin $\mathrm{D}_{3}$ (cholecalciferol)}

India is well known for its traditional, cultural and lingual diversity. It is a vast tropical country extending from $8.4^{\circ} \mathrm{N}$ latitude to $37.6^{\circ} \mathrm{N}$ latitude. Majority of its population live in areas receiving abundant sunlight throughout the year and hence it was assumed that Vitamin D (Vit D) deficiency is uncommon in India [1] and globally [2-5]. However from various studies and data available in the published literature, Vit D deficiency is very common in India in all the age groups and both sexes across the country [6-8]. Hence, Vitamin D status screening is essential as it allows for monitoring a patient's response to Vitamin D therapy and also evaluation of treatment effect therefore, samples providing immediate and reliable results are highly desirable.

Vitamin D is very important fat soluble vitamin in human and animal diet. It exists in two forms "viz", Vitamin $\mathrm{D}_{2}$ and $\mathrm{D}_{3}$.
Vitamin $\mathrm{D}_{3}$ (cholecalciferol) is synthesized endogenously from 7-dehydrocholesterol after ultraviolet irradiation or is absorbed from the diet $[9,10]$; plant/yeast derived ergocalciferol (Vitamin $D_{2}$ ) is formed exogenously by irradiation of ergosterol.

Vitamin D plays an important role in the maintenance of normal levels of calcium and phosphorus in the blood stream and is essential for the proper development and maintenance of bone [11]. Scientific evidence revealed that, it is not only associated with skeletal disorder but also plays animportant role in cancer, cardiovascular disease, autoimmune disease, hypertension, diabetes mellitus etc. [12-14] Vitamin D is not a single compound but is a family of compounds that exhibit Vit D activity. Its measurement is important as a clinical indicator of nutritional vitamin D deficiency, which is one of the causes of osteoporosis.

Clinical laboratory scientists have a diverse selection of Vit D testing methods from which to choose. The routine methods for measurement of vitamin $\mathrm{D}_{3}$ concentration in human plasma were based on competitive protein binding and used vitamin $\mathrm{D}$-binding protein and a tritium-labelled tracer. These methods were replaced by a simpler, rapid RIA, and a radio iodinated tracer was incorporated into the RIA in 1993 [15]. Quantitative HPLC assays have been developed based on

*Corresponding author: AK Tripathi, Biochemistry and Immunology Laboratory, Department of Biochemistry, University College of Medical Sciences (University of Delhi) and G.T.B. Hospital, Dilshad Garden, Delhi-110095, India, Tel: +9111-22582972-74 Extn 5210, +91- 9811259019; Fax: +91-11- 22590495; E-mail: aktripathiucms@gmail.com

Received December 10, 2014; Accepted August 13, 2015; Published Augus 17,2015

Citation: Kumar S, Chawla D,Tripathi AK (2015) An Improved and Sensitive Method for Vitamin D3 Estimation by RP-HPLC. Pharm Anal Acta 6: 410 doi: $10.4172 / 21532435.1000410$

Copyright: (c) 2015 Kumar S. This is an open-access article distributed under the terms of the Creative Commons Attribution License, which permits unrestricted use, distribution, and reproduction in any medium, provided the original author and source are credited. 
ultraviolet detection and reverse-phase separation. Recently, RP-HPLC methods for vitamin $\mathrm{D}_{3}$ in human plasma have been developed [16].

In contrast, to other areas of research like food analysis, the major challenge in the clinical study is the limitation of sample size. In spite of that, most of the available methods for vitamin $\mathrm{D}_{3}$ estimation has been developed on LC-MS/MS which increases the per sample cost of analysis. Therefore, we need to develop a simple, sensitive and economic RP-HPLC method of vitamin $\mathrm{D}_{3}$ estimation.

Here, we have developed and described a comparative study between two methods for measurement of vitamin $\mathrm{D}_{3}$ through HPLC. The present study was designed to make vitamin $\mathrm{D}$ estimation process easy to use, sensitive, rapid and economical at laboratory scale.

\section{Material and Methods}

\section{Apparatus}

The HPLC system used throughout this study consisted of a quaternary pump (Ultimate 3000, Thermo Fischer Scientific, USA), a manual sample injector with a $20 \mu \mathrm{l}$ sample loop, a degasser and photodiode array detector (Thermo Fischer Scientific, USA). The evaluation and quantification of output signals were made on Chromelion software version 6.80 which controls the whole liquid chromatographic system. The column used was a reversed phase, Acclaim $^{\mathrm{TM}} 300$, C18 column (150 x $4.6 \mathrm{~mm}$ i.d., $3 \mu \mathrm{m}$ particle size, $300 \AA$ diameter), procured from Thermo Fischer Scientific, USA. Two different mobile phases were used in the study, which were acetonitrile ( $\mathrm{pH}$ 5.19)/ methanol (pH 4.7$)(95: 5 \%)$ and methanol with $0.1 \%$ formic acid $(\mathrm{pH}$ $3.0) /$ water with $0.1 \%$ formic acid $(\mathrm{pH} 2.83)$ (95:5\%) respectively. The samples were passed at a flow rate of $0.4 \mathrm{~mL} \mathrm{~min}^{-1}$ mobile phase with a time window of $10 \mathrm{~min}$. The column temperature was held constant at $40^{\circ} \mathrm{C}$. The results were monitored at $265 \mathrm{~nm}$ wavelength for vitamin $\mathrm{D}_{3}$.

\section{Materials}

Chemicals and solvents used throughout this study such as methanol (Sigma Aldrich, Sweden) and acetonitrile (Sigma Aldrich, Sweden) were of high quality and HPLC grade. Vit.D ${ }_{3}$ standard was obtained from Sigma Aldrich, Sweden.

\section{Standard preparation}

A stock solution mixture of vit. $\mathrm{D}_{3}$ standard was prepared $(1 \mathrm{mg}$ $\mathrm{mL}^{-1}$ ) in methanol and stored at $-20^{\circ} \mathrm{C}$. Working solution mixture was prepared by diluting the stock solution in acetonitrile.

\section{Vitamin D extraction}

Vitamin D extraction was done by slight modification in the method of Turpeinen et al. [17]. To $0.5 \mathrm{ml}$ of sample/matrix, we added $350 \mu \mathrm{l}$ of methanol and 2-propanol in the ratio of 80:20 (v/v). The contents were mixed in a vortex mixer for 30s. Vitamin D was extracted by mixing two times ( $60 \mathrm{~s}$ each time) with $1 \mathrm{ml}$ of hexane. The phases were separated by centrifugation, and, the upper organic phase was transferred to a conical tube and dried under nitrogen. The residue was dissolved in appropriate volume of mobile phase.

\section{Linearity}

A stock solution of $1 \mathrm{mg} \mathrm{mL}^{-1}$ Vit $\mathrm{D}_{3}$ was prepared by dissolving $1 \mathrm{mg}$ Vit $\mathrm{D}_{3}$ lyophilized standard in $1 \mathrm{~mL}$ of methanol and then solutions of different concentrations $\left(0.5-5 \mathrm{ng} \mathrm{mL}^{-1}\right)$ for construction of calibration plots were prepared from this stock solution. The mobile phase was filtered through a $0.45 \mu \mathrm{m}$ membrane filter and passed through column at $0.4 \mathrm{~mL} \mathrm{~min}{ }^{-1}$ for column equilibration; the baseline was monitored continuously during this process. Detection was carried out at $\lambda_{\max } 265$ $\mathrm{nm}$. The prepared dilutions were injected in series, peak area was calculated for each dilution, and concentration was plotted against peak area.

\section{Accuracy}

Accuracy was determined by the standard addition method. Matrix (1x PBS + 0.1\% BSA, pH 7.2) was spiked with 3,5 and $15 \mathrm{ng} \mathrm{mL}^{-1}$ standard and the mixtures were analysed by the proposed method. The experiment was performed in triplicate. Recovery (\%), RSD (\%), and standard error (SE) were calculated for each concentration.

\section{Precision}

Precision was determined as both repeatability and intermediate precision, in accordance with ICH recommendations. Repeatability of sample injection was determined as intra-day variation and intermediate precision was determined by measurement of inter-day variation. For intra and inter-day variation study, we were chosen 0.5 and $2 \mathrm{ng} \mathrm{mL}^{-1}$ and 0.5-5 $\mathrm{ng} \mathrm{mL} \mathrm{m}^{-1}$ of Vit $\mathrm{D}_{3}$ standards, respectively.

\section{Limit of detection (LOD) and Limit of quantification (LOQ)}

LOD and LOQ were determined by the standard deviation $(\sigma)$ method. LOD and LOQ were determined from the slope, S, of the calibration plot, $\mathrm{S} y / \mathrm{x}$, by use of the formulae

$$
\begin{aligned}
& \mathrm{LOD}=3 \times \sigma / \mathrm{S} \text { and } \\
& \mathrm{LOQ}=10 \times \sigma / \mathrm{S} . \\
& \sigma=\text { Standard deviation, } \mathrm{S}=\text { Slope }
\end{aligned}
$$

\section{Efficiency}

Efficiency was calculated by using the following formula;

$$
\begin{aligned}
& \mathrm{N}=16\left(\mathrm{t}_{\mathrm{R}} / \mathrm{W}_{\mathrm{b}}\right)^{2} \\
& \left(\mathrm{~N}=\text { Efficiency, } \mathrm{t}_{\mathrm{R}}=\text { Retention time, } \mathrm{W}_{\mathrm{b}}=\text { Peak Width }\right)
\end{aligned}
$$

\section{Robustness}

The robustness of the method was determined to assess the effect of small but deliberate variation of the chromatographic conditions of the analyte and was determined by changing the flow rate and concentration of mobile phase upto $1 \%$.

\section{Result and Discussion}

In the present study we have developed HPLC method for sensitive and reliable detection of vitamin $\mathrm{D}_{3}$ by using two different mobile phases according to ICH guideline [18]. The results are divided into sub sections which are as shown below.

\section{Optimization of the chromatographic separation}

Separation was achieved on C18 column ( 150 X $4.6 \mathrm{~mm}$ i.d., $3 \mu \mathrm{m})$ in isocratic mode using two different mobile phases i.e acetonitrile: methanol (method I) and methanol: water with $0.1 \%$ formic acid (method II), in the ratio of 95:5 (v/v), respectively. Mobile phase was pumped into the column at flow rate of $0.4 \mathrm{~mL} \mathrm{~min}^{-1}$ and the detection of eluent was carried out at $265 \mathrm{~nm}$. The total run time was $10 \mathrm{~min}$ and the column was maintained at $40^{\circ} \mathrm{C}$. The retention time of vitamin $\mathrm{D}_{3}$ of method I and II was found 7.14 and 7.01 minutes respectively. Figure 1 shows the chromatogram of a standard Vit $\mathrm{D}_{3}$ by method I and II, respectively. 

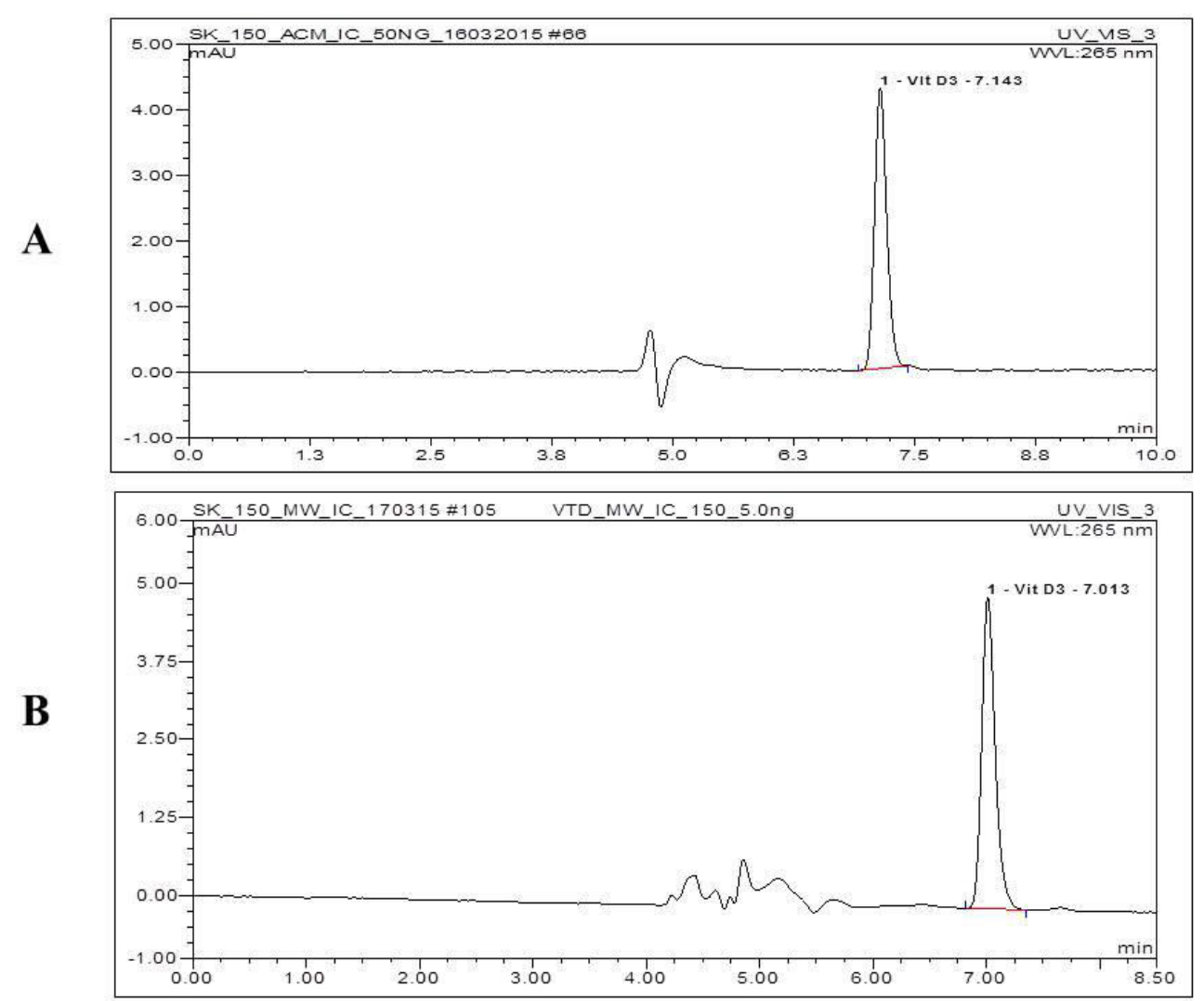

Figure 1: Chromatogram of a standard Vitamin $D_{3}$ using mobile phases (A) Acetonitrile : Methanol (95:5 v/v) (Method I) and (B) Methanol: Water with $0.1 \%$ formic acid (95:5 v/v) (Method II).

\section{System suitability}

The results (Mean $\pm \%$ RSD of six replicates) of the chromatographic parameters are shown in Table 1, indicating the good performance of the system.

\section{Linearity}

The standard having concentration $0.5,1,2,3,4,5 \mathrm{ng} \mathrm{mL}^{-1}$ Vit $\mathrm{D}_{3}$ were prepared by diluting the stock solution $\left(1 \mathrm{mg} \mathrm{mL}^{-1}\right)$ with mobile phase. Each of these standard solutions were injected three times into the HPLC-column and the peak area was calculated using Chromelion software version 6.80.Calibration Curve was prepared by plotting peak area (y) versus Vit $\mathrm{D}_{3}$ concentrations $\left(\mathrm{ng} \mathrm{mL}^{-1}\right)(\mathrm{x})$ for both the methods (Figure 2). The regression line $\left(r^{2}>0.99\right)$ demonstrates the excellent relationship between peak area and Vit $\mathrm{D}_{3}$ concentration in both the methods, over a concentration range of $0.5-5 \mathrm{ng} \mathrm{mL}^{-1}$ (Table 1). Turpeinen et al. reported that HPLC was preferred in terms of accuracy and precision in comparison to RIA and Diasorin [17].

\section{Accuracy}

The recovery of the methods, were determined by spiking matrix with different concentration of standard solution, by comparing the peak area obtained from the standard and from the spiked matrix. The value of Recovery (\%), RSD (\%) and SE indicate that method II is better than method I (Table 2). Formic acid in the mobile phase is known to improve peak shapes of the resulting separation. The other study used solid phase extraction (SPE) for recovery of Vit $\mathrm{D}_{3}$ and reported 55-

\begin{tabular}{|c|c|c|}
\hline Parameter & Method I & Method II \\
\hline Peak Area (Mean \pm \%SD ) & $0.6369 \pm 1.504$ & $0.6753 \pm 1.037$ \\
\hline Theoretical plates (EP) (Mean $\pm \% R S D$ & $15472.83 \pm 0.3301$ & $17800 \pm 0.3628 \%$ \\
\hline Retention time (Mean $\pm \% R S D)$ & $7.134 \pm 0.0289$ & $7.003 \pm 0.1474$ \\
\hline Linearity $\left(\mathrm{ng} \mathrm{mL}^{-1}\right)$ & $0.5-5$ & $0.5-5$ \\
\hline Regression equation & $0.1389 x-0.0262$ & $0.138 x-0.0025$ \\
\hline Correlation Coefficient $\left(\mathrm{R}^{2}\right)$ & 0.9929 & 0.996 \\
\hline LOD $\left(\mathrm{ng} \mathrm{mL}^{-1}\right)$ & 1.643 & 1.100 \\
\hline LOQ $\left(\mathrm{ng} \mathrm{mL}^{-1}\right)$ & 5.026 & 3.600 \\
\hline
\end{tabular}

*Indicates mean of three replicates, RSD= Relative standard deviation, SE= Standard error

Table 1: Chromatographic characteristics of system suitability, linearity and sensitivity.

\begin{tabular}{|c|c|c|c|c|c|c|}
\hline & \multicolumn{6}{|c|}{ Matrix Spiked with Vit $D_{3}$ standard } \\
\hline & \multicolumn{3}{|c|}{ Method I } & \multicolumn{3}{|c|}{ Method II } \\
\hline & $3 \mathbf{n g ~ m L}^{-1}$ & $5 \mathrm{ng} \mathrm{mL}^{-1}$ & $15 \mathbf{n g ~ m L}^{-1}$ & $3 \mathrm{ng} \mathrm{mL}^{-1}$ & $5 \mathrm{ng} \mathrm{mL}^{-1}$ & $\begin{array}{l}15 \mathrm{ng} \\
\mathrm{mL}^{-1}\end{array}$ \\
\hline $\begin{array}{c}\% \\
\text { Recovery }\end{array}$ & 68.87 & 78.74 & 69.91 & 75.18 & 81.49 & 87.43 \\
\hline$\%$ RSD & 3.16 & 9.30 & 0.77 & 4.22 & 3.81 & 2.78 \\
\hline SE & 0.004 & 0.035 & 0.189 & 0.007 & 0.012 & 0.746 \\
\hline
\end{tabular}

$85 \%$ recovery [19] whereas we used liquid-liquid extraction (LLE) and found the same, as LLE is less specific in comparison to SPE in case of Vit $\mathrm{D}_{3}$, due to small amount in circulation. 

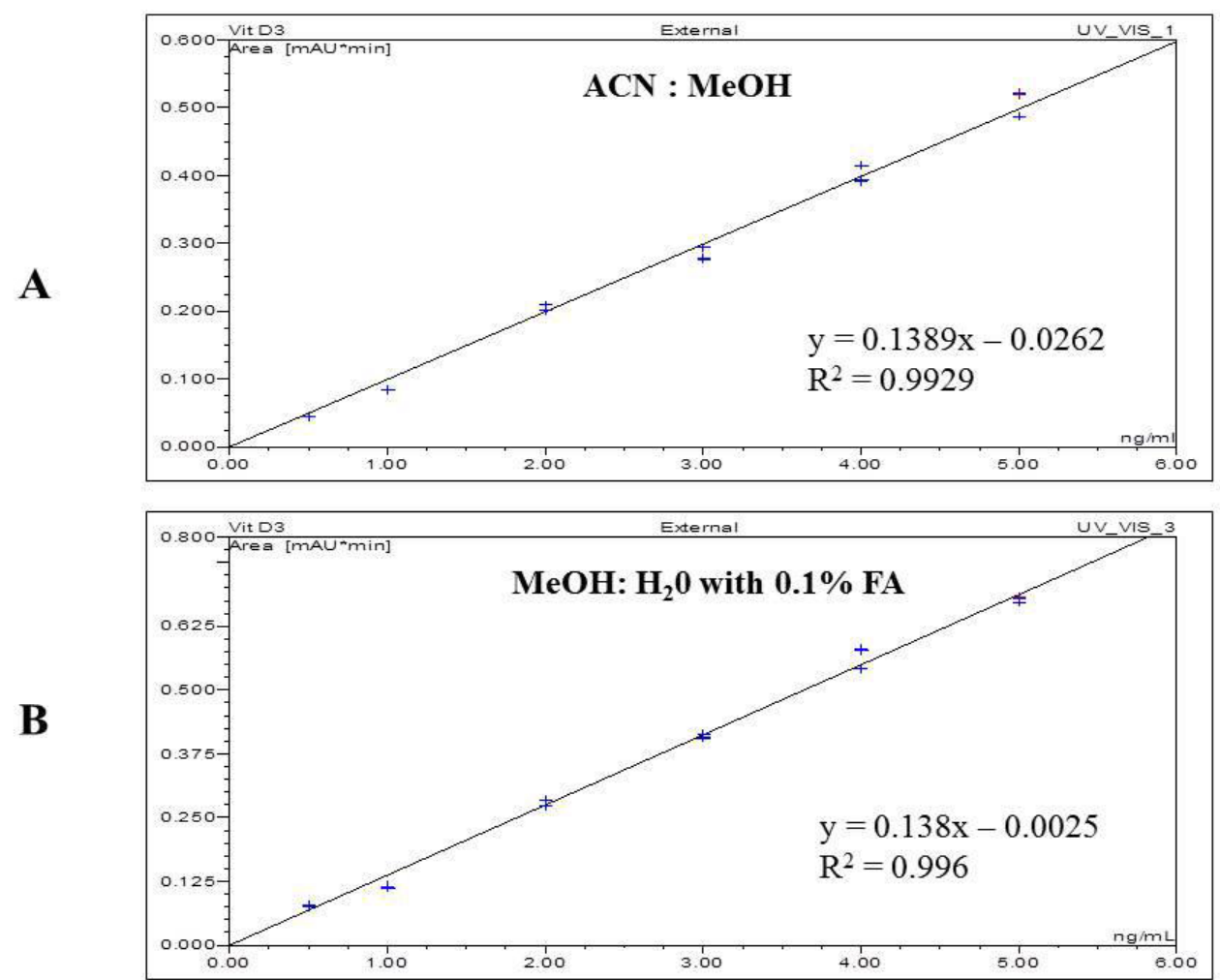

Figure 2: Calibration curve of Vitamin $D_{3}$ standard (A) Method I and (B) Method II.

\section{Precision}

The intra and inter-day precision were carried out for various concentration of standard in three replicates at different time intervals in the same day and at the same time in different days respectively. The $\%$ RSD and SE were calculated for both the methods and the low value of RSD (\%) of method II showed good precision in comparison to method I (Table 3). The other reported HPLC methods developed for vitamin $\mathrm{D}_{3}$ estimation showing within-batch and between-batch precision ranged from 0.83 to $<10 \%$ and 1.8 to $<12 \%$ respectively [20,21].

\section{Injection precision}

Injection precision was determined by injecting $5 \mathrm{ng} \mathrm{mL} L^{-1}$ of Vit $\mathrm{D}_{3}$ standard six times continuously and the injection precision repeatability of both the methods showed that the assay is repeatable (Table 4). The peak resolution of method II was found better $(>2)$ than method I $(<2)$.

\section{Sensitivity}

The limit of detection (LOD) and limit of quantitation (LOQ) for Vit $\mathrm{D}_{3}$ were evaluated by determining the average concentration that gives the signal three and ten times the background noise and was found $1.643(0.64), 5.02(2.0)$ and $1.1(0.44), 3.60(1.44) \mathrm{ng} \mathrm{mL}^{-1}(\mathrm{nmol}$ $\mathrm{L}^{-1}$ ) of method I and II, respectively (Table 1 ). In contrast to this the other HPLC methods reported the LOD ranged between 3 and 7.5 $\mathrm{nmol} / \mathrm{L}$ while the LOQ ranged between 10 and $17.5 \mathrm{nmol} / \mathrm{L}$ [22-26].

\section{Efficiency}

The efficiency was determined as mentioned in methodology section and it was found $15415(\mathrm{~N})$ and $17827(\mathrm{~N})$ for method I and II, respectively. The Chromlieon software generated number of theoretical plates also correlates with the efficiency data which reconfirms that method II was better competent than method I (Table 1).

\section{Robustness}

There were no significant change in the retention time of analyte was found when flow rate of the mobile phase has been changed (Table $5)$.

\section{Conclusion}

India is a developing country which is socio-economically poor. Although, plenty of sunlight is available throughout year, recent studies reported the Vitamin D deficiency in Indian population among all age groups. The person who is Vitamin D deficient is more prone to develop either non-communicable disease or auto-immune diseases. The available methods of Vit $\mathrm{D}_{3}$ diagnosis are very costly and most of them can't afford this. Therefore, we need to develop the simple, reliable and cost effective method of Vit $\mathrm{D}_{3}$ estimation. It is very well documented that analytical methods are sensitive and cost-effective in comparison to RIA or ELISA based method [17]. The separation of Vitamin $\mathrm{D}_{3}$ under different chromatographic conditions has been developed but the best separation was achieved on octadecyl-bonded stationary phase and the DAD detector at $\lambda_{\max } 265 \mathrm{~nm}$. We have checked different ratios of mobile phase combination and got good result at $\mathrm{ACN}$ : $\mathrm{MeOH}$ (95:5) and $\mathrm{MeOH}: \mathrm{H}_{2} \mathrm{O}$ (95:5) with $0.1 \%$ FA. When we were added FA to the mobile phase (method II) then we got better resolution in comparison to method I. The LOD and LOQ were also found relatively low in comparison to other existing methods, developed on HPLC. The developed RP-HPLC method for the determination of Vit $\mathrm{D}_{3}$ is simple, 
Citation: Kumar S, Chawla D, Tripathi AK (2015) An Improved and Sensitive Method for Vitamin D3 Estimation by RP-HPLC. Pharm Anal Acta 6: 410. doi:10.4172/21532435.1000410

Page 5 of 6

\begin{tabular}{|c|c|c|c|c|c|c|c|c|}
\hline \multirow{3}{*}{$\begin{array}{l}\text { Concentration } \\
\quad\left(\mathrm{ng} \mathrm{mL}^{-1}\right)\end{array}$} & \multicolumn{4}{|c|}{ Method I } & \multicolumn{4}{|c|}{ Method II } \\
\hline & \multicolumn{2}{|c|}{ Repeatability (intra-day precision)* } & \multicolumn{2}{|c|}{$\begin{array}{l}\text { Intermediate Precision (inter- day } \\
\text { precision) }{ }^{*}\end{array}$} & \multicolumn{2}{|c|}{ Repeatability (intra-day precision) ${ }^{*}$} & \multicolumn{2}{|c|}{$\begin{array}{l}\text { Intermediate Precision (inter- day } \\
\text { precision) }{ }^{\star}\end{array}$} \\
\hline & $\%$ RSD & SE & $\%$ RSD & SE & $\%$ RSD & SE & $\%$ RSD & SE \\
\hline 0.5 & 1.509 & 0.0004 & 5.605 & 0.0015 & 1.358 & 0.0004 & 3.624 & 0.0012 \\
\hline 1.0 & & & 6.766 & 0.0035 & & & 3.239 & 0.0016 \\
\hline 2.0 & 0.896 & 0.0011 & 5.814 & 0.0073 & 1.707 & 0.0024 & 2.251 & 0.0027 \\
\hline 3.0 & & & 2.127 & 0.0040 & & & 3.784 & 0.0067 \\
\hline 4.0 & & & 6.265 & 0.0162 & & & 2.657 & 0.0066 \\
\hline 5.0 & & & 5.467 & 0.0162 & & & 3.589 & 0.0105 \\
\hline
\end{tabular}

*Indicates mean of three replicates, RSD= Relative standard deviation, SE= Standard error Table 3: Precision analysis of method I and II.

\begin{tabular}{|c|c|c|c|c|c|c|}
\hline \multirow[b]{2}{*}{$\begin{array}{l}\text { Concentration (ng } \\
\left.\mathrm{mL}^{-1}\right)\end{array}$} & \multicolumn{3}{|c|}{ Method I } & \multicolumn{3}{|c|}{ Method II } \\
\hline & $\mathrm{RT}(\min )$ & Area & EP & RT (min) & Area & EP \\
\hline \multirow[t]{6}{*}{5.0} & 7.133 & 0.6390 & 15430 & 6.99 & 0.6718 & 17877 \\
\hline & 7.133 & 0.6417 & 15506 & 6.99 & 0.6799 & 17733 \\
\hline & 7.133 & 0.6354 & 15430 & 7.01 & 0.6837 & 17866 \\
\hline & 7.133 & 0.6399 & 15468 & 7.01 & 0.6714 & 17722 \\
\hline & 7.137 & 0.6190 & 15559 & 7.01 & 0.6651 & 17801 \\
\hline & 7.137 & 0.6469 & 15444 & 7.01 & 0.6800 & 17801 \\
\hline $\begin{array}{l}\text { Mean } \\
\text { \%RSD } \\
\text { SE }\end{array}$ & $\begin{array}{c}7.134 \\
0.0289 \\
0.0008\end{array}$ & $\begin{array}{c}0.6369 \\
1.504 \\
0.0039\end{array}$ & $\begin{array}{c}15472 \\
0.3301 \\
20.85\end{array}$ & $\begin{array}{c}7.003 \\
0.1474 \\
0.0042\end{array}$ & $\begin{array}{c}0.6753 \\
1.037 \\
0.0028\end{array}$ & $\begin{array}{c}17800 \\
0.3628 \\
26.36\end{array}$ \\
\hline
\end{tabular}

$\mathrm{RT}=$ Retention time, $\mathrm{EP}=$ Theoretical plates, $\mathrm{RSD}=$ Relative standard deviation, $\mathrm{SE}=\mathrm{Standard}$ error

Table 4: Result analysis of injection precision repeatability of method I and method II.

\begin{tabular}{|l|c|c|c|c|}
\hline Parameter & $\begin{array}{c}\text { Normal } \\
\text { Condition }\end{array}$ & Change Condition & Change in \%RSD & \\
\hline \multirow{3}{*}{ Flow Rate } & $0.4 \mathrm{~mL} \mathrm{~min}^{-1}$ & $0.396 \mathrm{~mL} \mathrm{~min}^{-1}$ & 0.1293 & Method I \\
\cline { 2 - 5 } & $0.4 \mathrm{~mL} \mathrm{~min}^{-1}$ & $0.404 \mathrm{~mL} \mathrm{~min}^{-1}$ & 0.1281 & 1.5127 \\
& $0.404 \mathrm{~mL} \mathrm{~min}^{-1}$ & Method II & 0.0312 & \\
\hline
\end{tabular}

Table 5: Robustness of the experiment.

precise, accurate, reproducible, cost effective and validated according to ICH guidelines [18]. Hence, both the methods can be used for the routine determination of vitamin $\mathrm{D}_{3}$ but method II is comparatively better than method I because formic acid improves the peak shape. Also, method I uses the acetonitrile in a major proportion whereas method II uses methanol, is a cheaper solvent in comparison to acetonitrile.

\section{Acknowledgment}

This work is supported through funds provided by Department of Health Research - Indian Council of Medical Research, Government of India, New Delhi under Multi-disciplinary research scheme.

\section{Conflict of Interest}

The authors declare that there is no conflict of interest.

\section{References}

1. Mehlawat U, Singh P, Pande S (2014) Current status of Vitamin-D deficiency in India. IPP (2): 328-335.

2. Luque de Castro MD, Fernández-Romero JM, Ortiz-Boyer F, Quesada JM
(1999) Determination of vitamin D3 metabolites: state-of-the-art and trends. J Pharm Biomed Anal 20: 1-17.

3. Holick MF (2007) Vitamin D deficiency. N Engl J Med 357: 266-281.

4. Kennel KA, Drake MT, Hurley DL (2010) Vitamin D deficiency in adults: when to test and how to treat. Mayo Clin Proc 85: 752-757.

5. Rosen CJ (2011) Clinical practice. Vitamin D insufficiency. N Engl J Med 364 248-254.

6. Harinarayan CV (2005) Prevalence of vitamin D insufficiency in postmenopausal south Indian women. Osteoporos Int 16: 397-402.

7. Marwaha RK, Sripathy G (2008) Vitamin D \& bone mineral density of healthy school children in northern India. Indian J Med Res 127: 239-244.

8. Harinarayan CV, Joshi SR (2009) Vitamin D status in India--its implications and remedial measures. J Assoc Physicians India 57: 40-48.

9. Holick MF (1995) Environmental factors that influence the cutaneous production of vitamin D. Am J Clin Nutr 61: 638S-645S.

10. Holick MF (2004) Vitamin D: importance in the prevention of cancers, type 1 diabetes, heart disease, and osteoporosis. Am J Clin Nutr 79: 362-371.

11. Weaver CM, Fleet JC (2004) Vitamin D requirements: current and future. Am J Clin Nutr 80: 1735S-9S.

12. Lappe JM, Travers-Gustafson D, Davies KM, Recker RR, Heaney RP (2007) Vitamin $D$ and calcium supplementation reduces cancer risk: results of a randomized trial. Am J Clin Nutr 85: 1586-1591.

13. Garland CF, Gorham ED, Mohr SB, Garland FC (2009) Vitamin D for cancer prevention: global perspective. Ann Epidemiol 19: 468-483.

14. Stechschulte SA, Kirsner RS, Federman DG (2009) Vitamin D: bone and beyond, rationale and recommendations for supplementation. Am J Med 122 793-802. 
Citation: Kumar S, Chawla D, Tripathi AK (2015) An Improved and Sensitive Method for Vitamin D3 Estimation by RP-HPLC. Pharm Anal Acta 6: 410. doi: $10.4172 / 21532435.1000410$

15. Terry AH, Sandrock T, Meikle AW (2005) Measurement of 25-hydroxyvitamin $\mathrm{D}$ by the Nichols ADVANTAGE, DiaSorin LIAISON, DiaSorin RIA, and liquid chromatography-tandem mass spectrometry. Clin Chem 51: 1565-1566.

16. Wallace AM, Gibson S, de la Hunty A, Lamberg-Allardt C, Ashwell M (2010) Measurement of 25-hydroxyvitamin $D$ in the clinical laboratory: current procedures, performance characteristics and limitations. Steroids 75: 477-488.

17. Turpeinen U, Hohenthal U, Stenman UH (2003) Determination of 25-hydroxyvitamin D in serum by HPLC and immunoassay. Clin Chem 49: 1521-1524.

18. (1996) Validation Of Analytical Procedures: Text And Methodology, ICH Harmonized Tripartite guidelines.

19. Ding S, Schoenmakers I, Jones K, Koulman A, Prentice A, et al. (2010) Quantitative determination of vitamin D metabolites in plasma using UHPLCMS/MS. Anal Bioanal Chem 398: 779-789.

20. Glendenning P, Taranto M, Noble JM, Musk AA, Hammond C, et al. (2006) Current assays overestimate 25-hydroxyvitamin D3 and underestimate 25-hydroxyvitamin D2 compared with HPLC: need for assay-specific decision limits and metabolite-specific assays. Ann Clin Biochem 43: 23-30.

21. Mata-Granados JM, Quesada Gómez JM, Luque de Castro MD (2009) Fully automatic method for the determination of fat soluble vitamins and vitamin $\mathrm{D}$ metabolites in serum. Clin Chim Acta 403: 126-130.

22. Alvarez JC, De Mazancourt $P$ (2001) Rapid and sensitive high-performance liquid chromatographic method for simultaneous determination of retinol, alpha- tocopherol, 25-hydroxyvitamin D3 and 25-hydroxyvitamin D2 in human plasma with photodiode-array ultraviolet detection. J Chromatogr B Biomed SciAppl 755: 129-135.

23. Brunetto MR, Obando MA, Gallignani M, Alarcón OM, Nieto E, et al. (2004) HPLC determination of Vitamin $\mathrm{D}(3)$ and its metabolite in human plasma with on-line sample cleanup. Talanta 64: 1364-1370.

24. Roth HJ, Schmidt-Gayk H, Weber H, Niederau C (2008) Accuracy and clinical implications of seven 25-hydroxyvitamin D methods compared with liquid chromatography-tandem mass spectrometry as a reference. Ann Clin Biochem 45: 153-159.

25. Jakobsen J, Bysted A, Andersen R, Bennett T, Brot C, et al. (2009) Vitamin D status assessed by a validated HPLC method: within and between variation in subjects supplemented with vitamin D3. Scand J Clin Lab Invest 69: 190-197.

26. Narayanaswamy R, lyer V, Khare P, Bodziak ML, Badgett D, et al. (2015) Simultaneous determination of oxysterols, cholesterol and 25-hydroxy-vitamin D3 in human plasma by LC-UV-MS. PLoS One 10: e0123771. 